\title{
Psychology from Neurobiology
}

\author{
Mukundan CR* \\ Axxonet Brain Research Laboratory, India
}

*Corresponding author: Mukundan CR, Axxonet Brain Research Laboratory, Axxonet System Technologies, Bangalore, India, Tel: 9845166355, Email: crmukundan@gmail.com

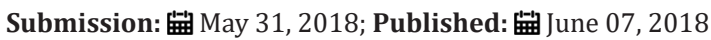

\begin{abstract}
The two functions systems that have contributed to the origin of Psychology has been emotional arousal and cognitive processes. Emotional arousal has provided the basic driving f orce, whereas cognitive processing contributed to making sensory-motor contacts with reality. Complex cognitive processing facilitated extensive knowledge base of the sensory-motor contacts, as well as helped to create virtual realities. Emotional arousal supported the genesis of responses and actions, as per the cognitive judgments made in the system. The article deals with brief account of the complex nature of interactions between the two systems and how psychology - the mind and behavior emerged from the interactions.
\end{abstract}

\section{Mini Review}

A neurobiological system consists of a physical system which accepts signals from outside, process them and make responses using the same physical system. Signal processing at the sensory and motor domains have contributed to the creation of immensely enriched processing systems, most of which we call the cognitive processing. Man has built such processing systems using comparable processing functions, which we call artificial intelligence and the associated processing abilities are used in multiple applications. The cognitive abilities of the brain and their corrections are used for all survival needs, as well as for creation of new realities, which have helped change in parts and full the scope, opportunities, and the functional abilities to meet and change the realities of the universe. These in turn, have been changing the scope and living styles of millions of human beings over thousands of years. Equally important is the presence and utilization of a driving force of the system, without which the system has no life and it perishes.

The driving force has been proposed as that of emotion [1-3], though emotion is always experienced and recognized through cognitive molding. Without the drive emotionally constituted, one cannot intentionally raise even the little finger. Though the driving force provides unique energy for life, for all its responses, actions, and the psychobiological activities of the system, it is also under the direct and indirect control of the cognitive processes. Cognitive processes help mold the emotional arousal into positive or negative experience, or with nil value recognized by the individual. The cognitively molding of emotional state provides specific positive or negative value to the individual, and the responses and actions initiated by the drive when the emotional arousal reaches a Critical Limit of Potentiation (CLP, 4), well before one is aware of the presence of the initiation of the action within [5-10].
The entire spectra of psychological states may be produced in each living being well before one becomes aware of the initiation of the action, as action has automatically been initiated, when the drive has reached the CLP state. Awareness of a negative state generated after the initiation of an action may shape into states of depression, fear, aggression and multiples of associated behavioral manifestations, which may form further hindrance to routine life of the individual. Emotional experience is the unique subjective

effect that take place within each individual, and each experience is shaped by the cognitive processes applied on the incoming signals and own responses to them. The cognitive judgments of the sensory-motor contacts mold and render the emotional state of an individual into specific emotional experiences and expressions. Molding of emotional state through cognitive processing is indeed the complex result of several self-trained methods, which one learns from birth, and develops in complex forms and effects during development and growth. One learns to identify emotional arousal only when its presence is molded in a specific manner by accompanying cognitive processes.

One may seldom use any effort to experience emotional arousal without any accompanying cognitive judgments, which would in turn mold the accompanying emotional state. This has been considered facilitated by carrying out mentally and physically, which may contribute to devotion and love or negative effects to others. Once expectations of any gainful return effects accompany, judgments of its presence or absence would accordingly shape the emotional arousal within. However, these mental processes may facilitate unbiased emotional responses only when one could direct the drive without expecting any personally gainful, but unbiased 
beneficial results. This is indeed an extremely difficult task for most of the human beings.

Ancient Vedic philosophy instructs individuals to learn to restrain from automatic cognitive molding of emotional arousal into positive or negative values, and learn to carry out the cognitive judgments carefully, considering its beneficial effects to the system one represents, and then make the cognitive judgment which would release the associated emotional effects [2]. The mental state which restrains one from automatic emotional responses is called the state of "Sthita Prajna" [11,12]. We always speak about a few great life forces like Jesus Christ, Goutam Budha, and some others, and their eminent followers, who led life of love and devotion only to other living beings. They have served as the greatest living examples with the possession of such unique emotional arousal and their utilization in life. Positively molded emotional arousal, created and utilized for multiple achievements in life is always considered the rightful utilization of emotional drive in life, which has helped all creations by mankind.

On the other hand, negative emotions created through cognitive judgments have also been extensively utilized by mankind for destruction of other fellow beings, who could not agree or support their personal pursuits and values. They explain both positive and negative molding effects, whether their needs have rational justifications or not. They have been justifying presence of such irrational emotional drives and their utilizations for the destruction of others, who do not share their ideas and values. This is happening at social and individual levels, and there are large social institutions, which support and carry out such destructive actions and responses. On the other hand, positive emotional judgments and their utilizations by initiation of new actions and responses have almost always helped weaker human beings and those who need to overcome painful and even tragic moments of life.

Emotional drive is still a strange life force, about which we know very little, except its manifestations, experiences and applications. On the other hand, component of such drive mixed with cognitive processes which may include preattentive processing, recognition, thinking, awareness created through self-monitoring $(13,14)$ of encoded information and experiences, through online processing and remembrance $(15,16)$, which were traditionally integrated into the concept of consciousness. Electrical, mechanical, neurochemical and other scientific methods serve the preservation and recreation of the emotional force needed essentially for the initiation of actions and responses. However, emotional energy available and its varied positive and negative experiences and expressions, physically and virtually created, as seen in man, have never been replicated in such varied forms, anywhere else (17-19). Mankind has already successfully created resources with cognitive processing abilities and have been utilizing them at every juncture in life. We have traditionally identified the presence of this energy as a spiritual one, since spiritual dimension could not be scientific explained and justified. It is accepted that the same life force may be present in all living beings, including plants and animals, though their complex manifestations in the forms of experiences and expressions are the results of presence of other functional systems generated and developed within the brain and the body.

\section{References}

1. Mukundan CR (2017) Emotion-The Driving Force, Red Shine Publication, Ahmedabad, India, pp. 1-273.

2. Mukundan CR, Kacker P (2018a) Molding emotion while cognitively processing physical \& virtual realities. EC Neurology 10(5): 354-366.

3. Mukundan CR, Kacker P (2018b) Emotional Arousal-the Driving Force of Life. Journal of Psychology \& Clinical Psychiatry 9(3): 1 -12.

4. Mukundan CR, Ajayan P, Kacker P, Chetan SM, Vyas JM (2014) Violent Behavior: Absence of Social Conditioning of Drives during Neurodevelopmental Stages. IJIP 2(1): 1-33.

5. Mukundan CR, J Singh Ray, R Desai N (1986) Bereitschaftspotential in alcoholics. Biol Psych 21(11): 1090-1092.

6. Libet B (1985) Unconscious cerebral initiative and the role of conscious will in voluntary action. Behav Brain Res 8(4): 539-566.

7. Libet B (1999) Do we have free will? Journal of Consciousness Studies 6: 47-57.

8. Deecke L, Eisinger H, Kornhuber HH (1980) Comparison of Bereitschaftspotential, promotion positivity and motor potential preceding voluntary flexion and extension movements in man. Progress in Brain Research 54: 171-176.

9. Matsuhashi M, Hallett M (2008) The timing of the conscious intention to move. Eur J Neurosci 28(11): 2344-2351.

10. Soon CS, Brass M, Heinze HJ, Haynes JD (2008) Unconscious determinants of free decisions in the human brain. Nature Neuroscience 11(5): 543545 .

11. Bhattacharyya Kokileswar, Śaṅkarācārya (1979) "An introduction to Adwaita philosophy: a critical and systematic exposition of Sankara school of Vedanta". Bharatiya Pub House, Varanasi, India.

12. Mukundan CR, Arun Sasidharan, Priyanka Kacker (2017) Sthita Prajna: A State to Control Cognitive Molding of Emotional Arousal. In Jitendra Mohan (Ed.), Emerging Contours of Excellence, Publication Bureau, Punjab University, Chandigarh, p. 24-40.

13. Mukundan CR (1999) Power of Words: Neuro-cognitive Approach for Understanding Brain Mechanisms of Awareness. In: Sangeetha Menon, et al. (Eds.), Scientific and Philosophical Studies on Consciousness. National institute of Advanced Studies, Bangalore, India, pp. 127-136.

14. Mukundan CR, Ajayan P (2011) Awareness and Self-Image. Indian Journal of Clinical Psychology 38(1): 37- 48.

15. Mukundan CR (2007) Brain Experience: Neuroexperiential Perspectives of Brain-Mind. Atlantic Publishers, New Delhi.

16. Mukundan CR, Sumit S, Chetan SM (2018) Brain Electrical Oscillations Signature Profiling (BEOS) for Measuring the Process of Remembrance. EC Neurology 8(6): 217-230.

17. Mukundan CR (2016) Assigning Meaning to Emotional Arousal. International Journal of Indian Psychology. Red Shine Publication, Ahmedabad, India, 3(4): 11-33, 61.

18. Mukundan CR (2016) Emotional Experience and Expressions. International Journal of Indian Psychology 3(3): 1-28.

19. Mukundan CR (2016) Emotion-Arousal and Control. International Journal of Indian Psychology 3(2): 1-20. 


\begin{tabular}{|l|l|} 
PPRS & \multicolumn{1}{c}{$\begin{array}{c}\text { Psychol Psychother Res Stud } \\
\text { Psychology and } \\
\text { Psyctotherpy. } \\
\text { Research Study }\end{array}$} \\
Benefits of Publishing with us
\end{tabular}

For possible submissions Click Here

Submit Article

For possible submissions Click Here 